\title{
Constipation Risk in Patients Undergoing Abdominal Surgery
}

\author{
Sevim Celik ${ }^{1, *}$; Nurdan Yalcin Atar ${ }^{1}$; Nilgun Ozturk ${ }^{1}$; Guler Mendes ${ }^{1}$; Figen Kuytak ${ }^{1}$; Esra \\ Bakar ${ }^{1}$; Duygu Dalgiran ${ }^{1}$; Sumeyra Ergin ${ }^{1}$ \\ ${ }^{1}$ Nursing Department, Bulent Ecevit University, Zonguldak Health School, Zonguldak, Turkey \\ *Corresponding Author: Sevim Celik, Nursing Department, Bulent Ecevit University, Zonguldak Health School, Zonguldak, Turkey. Tel:+90-05327832989, E-mail: sevimakcel@yahoo.com
} Received: September 14, 2014; Revised: March 21, 2015; Accepted: April 10, 2015

\begin{abstract}
Background: Problems regarding bowel elimination are quite common in patients undergoing abdominal surgery.
Objectives: To determine constipation risk before the surgery, bowel elimination during postoperative period, and the factors affecting bowel elimination.

Patients and Methods: This is a cross-sectional study. It was conducted in a general surgery ward of a university hospital in Zonguldak, Turkey between January 2013 and May 2013. A total of 107 patients were included in the study, who were selected by convenience sampling. Constipation Risk Assessment Scale (CRAS), patient information form, medical and nursing records were used in the study.

Results: The mean age of the patients was found to be $55.97 \pm 15.74$ (year). Most of the patients have undergone colon (37.4\%)and stomach surgeries (21.5\%). Open surgical intervention (83.2\%) was performed on almost all patients (96.3\%) under general anesthesia. Patients were at moderate risk for constipation with average scores of 11.71 before the surgery. A total of 77 patients (72\%) did not have bowel elimination problem during postoperative period. The type of the surgery $(\mathrm{P}<0.05)$, starting time for oral feeding after the surgery $(\mathrm{P}<0.05)$, and mobilization $(\mathrm{P}<0.05)$ were effective on postoperative bowel elimination.

Conclusions: There is a risk for constipation after abdominal surgery. Postoperative practices are effective on the risk of constipation.
\end{abstract}

Keywords: Constipation; Abdomen; Surgery, Risk Factors; Nurses; Patients

\section{Background}

Abdominal surgery is performed to treat diseases of stomach, bile duct, liver, spleen, pancreas, small intestine, and large intestine. Complications, which occur after abdominal surgery are specific to gastrointestinal system as in preoperative period $(1,2)$. Problems regarding bowel elimination are quite common in patients who underwent abdominal surgery. It was reported that this ratio was $25 \%$ to $40 \%$ in hospitalized patients who underwent surgery $(3,4)$. Bowel frequency is influenced by several factors, including intake of dietary factors, emotional status, immobility, previous bowel elimination history, and psychological morbidity after abdominal surgery $(5,6)$.

There is no complete definition for constipation, which is a common problem. In previous studies, constipation was defined as a delay and suffer in the removal of fecal contents within the rectum, hard and dry stool, less than 3 defecations in a week, difficulty during defecation and inability to completely excrete stool $(2,3)$. In order to provide standardization in several constipation definitions, Rome I criteria were generated by Rome Committee in 1989; Rome II criteria were developed by the revision of these criteria in 1996; and finally Rome III criteria were generated in Los Angeles in 2006. According to Rome II criteria, constipation is defined as the presence of at least two symptoms such as difficulty in defecation for at least 3 months since last year, straining to evacuate the stool of at least one fourth of the time or more, complete obstruction, feeling of incomplete rectal emptying, need for manual evacuation of the rectal region, fewer than 3 bowel movements per week, and the inability to achieve a soft bowel movement. According to the Rome III criteria, these complaints should have persisted at least $\geq 6$ months and have been experienced during at least $10 \%$ of the last 3 months. The presence of 3 or more days of constipation symptoms is also necessary (3, 7-9).

Constipation is an important symptom affecting postoperative healing, quality of life, comfort, respiratory and circulatory systems of the patients, and quality of nursing care in the postoperative period (1,3,10-12). Place of surgical intervention, type of anesthesia, trauma of intestines during the operation, duration of postoperative immobility, suppression of defecation feeling, use of bedpan, inability to protect privacy, inability of the patients to verbally express their discomfort, using opioids/non opioids analgesic, fluid intake and alterations in dietary habits are effective in bowel elimination in the early postoperative period $(6,10-13)$. 
Celik S et al.

Nursing care has a significant role in the management of constipation after abdominal surgery. Nurses should identify constipation risk by a standard risk scale during preoperative period $(7,14-16)$. Risk assessment is highly important in the planning of nursing practice during postoperative period. Nurses should monitor gas exchange, elimination activity, mobilization, oral feeding, and liquid intake of the patients soon after abdominal surgery (1).

\section{Objectives}

A limited number of studies have investigated the preoperative and postoperative risk factors for constipation in the patients undergone abdominal surgery $(17,18)$. The purpose of this study was performed to determine constipation risk before surgery. The study also aimed to determine bowel elimination during postoperative period and the factors that are effective in achieving bowel elimination. The research questions were as follows:

-What is the patient's constipation risk before surgery?

-What is the status of the patient's bowel excretion after surgery?

-What is the relationship between patient's characteristics and status of bowel elimination?

\section{Patients and Methods}

\subsection{Study Design and Setting}

This is a cross-sectional study, which was conducted in a general surgery ward of a university hospital referral center in Zonguldak, Turkey between January 2013 and May 2013. Hospital is a university hospital with 500 beds and 23 wards. There are 20 beds in a general surgery ward of hospital.

\subsection{Samples}

The study population was made of 150 patients who had undergone abdominal surgery. Patients were selected by convenience sampling. All patients who met the inclusion criteria were included into the sample. The sample consisted of 107 patients who met the inclusion criteria and accepted to participate in the study.

The inclusion criteria for sample were as follows: 1) Patients should not have irritable bowel syndrome, 2) They underwent abdominal surgery such as stomach, gall bladder, liver, spleen, pancreas, small intestine, and large intestine, 3) They were hospitalized for at least 3 days after abdominal surgery, 4) They did not develop acute complications during preoperative period, 5) They were 18 years of age or older, 6 ) they were able to read and write Turkish, and 7) They were able to verbally communicate.

Of the 170 patients, 15 patients were not willing to participate in the study during postoperative period, $23 \mathrm{pa}$ tients were discharged from hospital before the third day, and 5 patients were not effective in verbal commu- nication. This study was conducted on the remaining 107 patients.

\subsection{Instruments}

Data were collected by patient data form, Constipation Risk Assessment Scale (CRAS), medical and nursery records.

Patient Information Form: This form was developed on the basis of the relevant literature $(3,7,18,19)$. The patient information form consisted of two sections. The first section included 11 closed-ended questions about patients' characteristics such as age, sex, body mass index, marital status, educational level, professional status, economic status, life style, previous surgical intervention, previous constipation, and non-drug methods of constipation management. The second section included 15 questions regarding clinical characteristics of the patient such as duration of hospitalization, type of the operation, type of anesthesia, form of the operation, postoperative onset of oral feeding, postoperative mobilization time, analgesics, and antiemetic drugs used after the operation and the presence of bowel elimination 3 days after the surgery.

Constipation Risk Assessment Scale (CRAS): This scale (Figure 1) was designed by Richmond (18) for nurses to assess the patients' risk of constipation. It has 4 subscales, including risk factors such as gender, mobility, fiber intake, fluid intake, personal beliefs, use of hospital toilets or commodes/bedpans, pathophysiological conditions, and pharmacological agents. Within each section, the subcategories were generally arranged in ascending numerical order and a higher total score represents increased risk of constipation. According to the total CRAS score, individuals were assessed as 'high,' 'medium,' or 'low' risk of constipation (15) (Figure 1).

Cronbach $\alpha$ coefficient of this scale was 0.50 in a study on orthopedic patients by Richmond and Wright (15). CRAS's validity and reliability tests in Turkey were performed by Kutlu et al. (7). The scale was found to be valid and reliable for use in Turkey on orthopedic patients. Testretest comparison and internal consistency were used to assess the reliability of the instrument by Kutlu and associates. Assessment of internal consistency was done by calculating Cronbach values for 152 patients. ICCs and values between 0.50 and 0.75 were considered moderate reliability (7). According to the effect size comparisons, the most effective variable on the CRAS score was perception of constipation risk requirement $(\mathrm{ES}=0.83)$. The overall score and subsection score correlations were also found acceptable $(r=0.47$ - 0.57). The Cronbach $\alpha$ coefficient of the Turkish form was 61.9. In this study, the mean of Cronbach $\alpha$ value was calculated to be 0.59 and floor/ceiling effects were not evaluated.

Medical and Nursing Records: Information regarding surgery performed to patients, type of the operation and anesthesia, switch to oral feeding, mobilization, medicines used and status of providing elimination were obtained from the nurse and clinicians follow-up forms in the file. 
Celik S et al.

CONSTIPATION RISK ASSESSMENT SCALE $\odot$ Janice $P$ Richmond (2001) Unpublished: University of Ulster

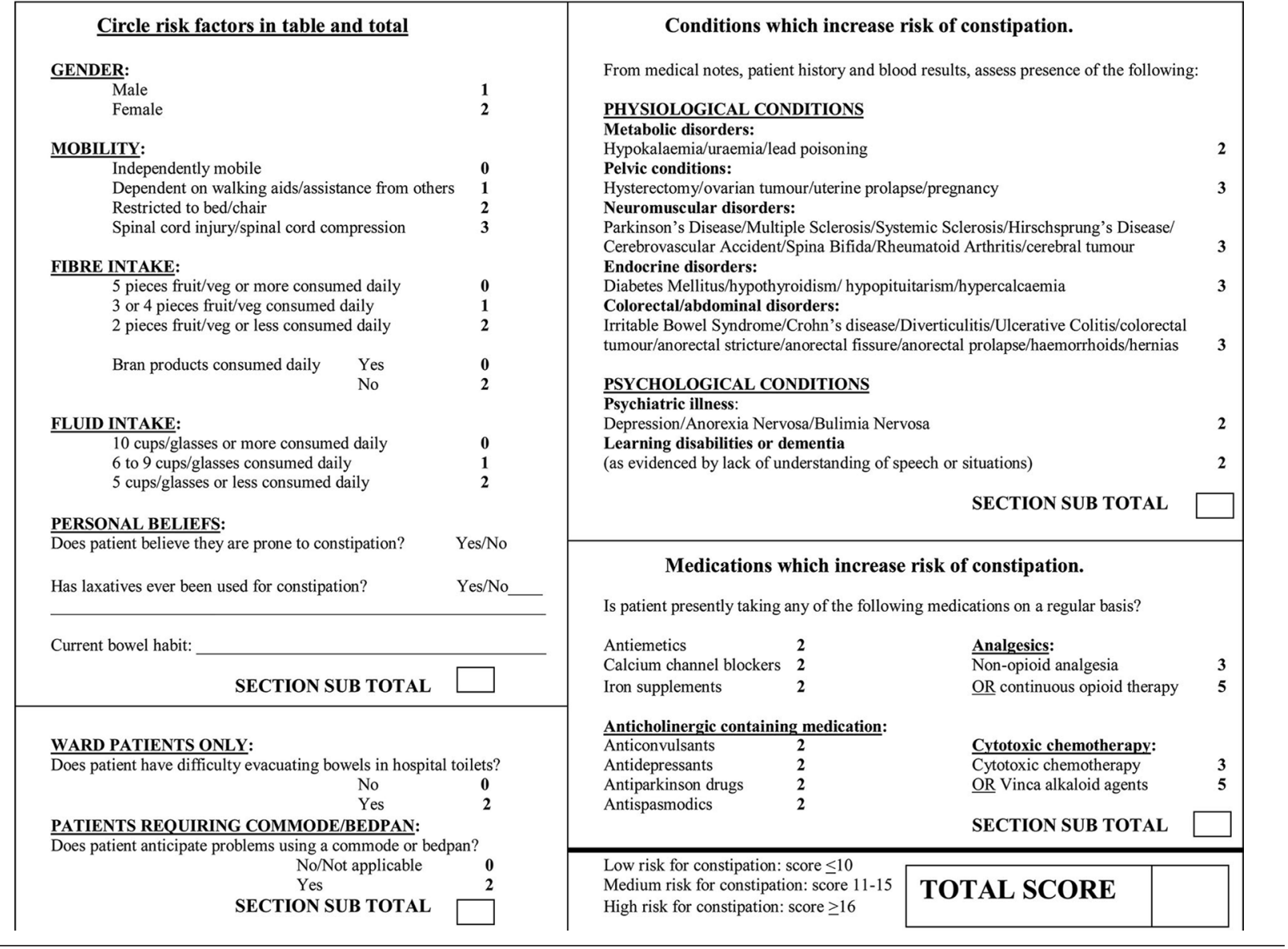

Figure 1. Constipation Risk Assessment Scale

\subsection{Procedure}

Data were collected by using indicated measurement instruments. Four interviews were performed in the morning each lasting for 10 minutes by one researcher. The first section of the patient information form and CRAS were collected by interviewing with the patients during preoperative period. Another interview was performed with patients in the morning of next day after the surgery; and their status of mobilization, oral feeding, bowel elimination, and probable problems during postoperative period were evaluated. At the same time, similar data on patients were checked from the patients' file, and then treatments used were recorded. The other interviews were performed postoperatively on the second day morning, which comprise gathering information with respect to general condition of the patient, ability of mobilization, oral feeding status, bowel elimination, its frequency if provided, its amount, consistency and color and other information from patient's file. It was accepted that bowel excretion was not provided in patients who did not show defecation at the second night of postoperative day.

\subsection{Data analysis}

Data were entered into SPSS 16.00 for Windows (SPSS Inc., Chicago, IL, USA). Patients' characteristics were assessed by number, percentage, and mean and standard deviation calculations. The $\chi^{2}$ and Fisher Exact tests were performed for the nominal variables between sociodemographic characteristics and bowel elimination problem. Moreover, t test was applied to analyze the differences between the averages of two groups. Mann-Whitney $U$ test was applied where the distribution of the data was not normal. The Kruskal-Wallis test was adopted in the case of non-homogenous multiple groups. For determining the relation between the numeric variables, the Pearson Correlation Coefficient test was applied. The normality distribution of variables was assessed using the Kolmogorov-Smirnov test. P values of 0.05 or less were considered statistically significant.

\subsection{Ethical Considerations}

This study was performed in accordance with the guidelines of the Declaration of Helsinki. The ethical board of 
Celik S et al.

the university approved the study (code: 2012/24). Before the survey, written permission from head physician of the university was obtained, and the patients were informed that the collected information would be kept anonymous and their participation was completely voluntary. The patients consented verbally.

\section{Results}

The mean age of the patients was found to be $55.97 \pm$

\begin{tabular}{lc}
\hline Table 1. Characteristics of the Patients ${ }^{\text {a }}$ & \\
\hline Characteristics & Frequency \\
\hline Age, $\mathbf{y}$ & $55.97 \pm 15.74$ \\
\hline Gender & \\
\hline Female & $50(46.7)$ \\
\hline Male & $57(53.3)$ \\
\hline Marital status & \\
\hline Married & $93(86.9)$ \\
\hline Single & $14(13.1)$ \\
\hline Educational level & $19(17.8)$ \\
\hline Illiterate & \\
\hline Primary school & $58(54.2)$ \\
\hline High school & $20(18.7)$ \\
\hline University and higher & $10(9.3)$ \\
\hline Professional status & \\
\hline Self-employed & $14(13.1)$ \\
\hline Office job & $6(5.6)$ \\
\hline Housewife & $41(38.3)$ \\
\hline Retired & $37(34.6)$ \\
\hline Other (student, worker) & $9(8.4)$ \\
\hline Pevious surgical intervention history & \\
\hline Percentages were calculated according to this number. \\
\hline Nonic status \\
\hline Good \\
\hline Bad
\end{tabular}

15.74 (year). With respect to the abdominal surgery, 53.3\% were male, $86.9 \%$ married and $54.2 \%$ secondary school graduates. One third of the patients were housewives (38.3\%) and retired (34.6\%). The majority of the patients reported a moderate income level (89.7\%). Most of them had an active life style (72.0\%); body mass index showed that patients were overweight (41.1\%) and normal (27.1\%). About $58.9 \%$ of the patients had a constipation history and nearly all practiced alternative methods. Furthermore, $64.5 \%$ of the patients underwent previous surgical intervention.

Most of the patients had undergone colon (37.4\%) and stomach surgeries (21.5\%). Open surgical intervention (83.2\%) was performed on almost all patients (96.3\%) under general anesthesia. The patients' mean duration of surgery was $200.47 \pm 96.80$ minutes. A total of $35.5 \%$ of the patients were mobilized on the second postoperative day and $33.6 \%$ on the first day; and the mean duration was found to be $1.78 \pm 0.71$ (day). Most of the patients ( $80.4 \%$ ) started oral feeding on the second postoperative day; and the mean duration was $2.90 \pm 0.88$ (day). Besides, nearly half of the patients were using non-opioids analgesics (46.7\%) and $41.1 \%$ antiemetic after the surgery.

Table 2. Patients' Characteristics Regarding Surgical Intervention Period ${ }^{\text {a }}$

\begin{tabular}{lc}
\hline Variable & Frequency \\
\hline Duration of current operation, min & $200.47 \pm 96.80$ \\
\hline Duration of hospitalization, $\mathbf{~}$ & $6.81 \pm 5.46$ \\
Type of the operation & \\
\hline Stomach & $23(21.5)$ \\
\hline Colon & $40(37.4)$ \\
\hline Gall bladder & $13(12.1)$ \\
\hline Hernia repair & $13(12.1)$ \\
\hline Other & $18(16.8)$ \\
\hline Type of anesthesia & \\
\hline General & $103(96.3)$ \\
\hline Epidural & $4(3.7)$ \\
\hline Form of the operation & \\
\hline Open & $89(83.2)$ \\
\hline Laparoscopic & $18(16.8)$ \\
\hline Postoperative mobilization time & $1.78 \pm 0.71$ \\
\hline Day 0 & $30(28.0)$ \\
\hline Day 1 & $36(33.6)$ \\
\hline Day 2 & $38(35.5)$ \\
\hline Day 3 & $3(2.8)$ \\
\hline Postoperative oral feeding & $2.90 \pm 0.88$ \\
\hline Yes & $86(80.4)$ \\
\hline No & $21(19.6)$ \\
\hline Postoperative analgesic use & \\
\hline None & $27(25.2)$ \\
\hline Non-opioid use & $50(46.7)$ \\
\hline Opioid use & $30(28.0)$ \\
\hline Postoperative antiemetic use & \\
\hline Yes & $44(41.1)$ \\
\hline No & $63(58.9)$ \\
\hline Data are presented as No.(\%) or Mean \pm SD. \\
\hline
\end{tabular}


Celik S et al.

\begin{tabular}{|c|c|c|c|}
\hline Characteristics & No. $(\%)$ & Score (Min-Max) & Score $(X \pm S D)$ \\
\hline Subscale 1 & & $1-8$ & $4.93 \pm 1.86$ \\
\hline \multicolumn{4}{|l|}{ Gender } \\
\hline Female & $50(46.7)$ & & \\
\hline Male & $57(53.3)$ & & \\
\hline \multicolumn{4}{|l|}{ Mobilization } \\
\hline Independent movements & $56(52.3)$ & & \\
\hline Dependent for walking/ receiving help from others & $47(43.9)$ & & \\
\hline Bound to bed and chair/limited & $4(3.7)$ & & \\
\hline Spinal cord injury/spinal cord pressure & $0(0.0)$ & & \\
\hline \multicolumn{4}{|l|}{ Fiber intake } \\
\hline Consuming 5 slices or more fruits/vegetables per day & $42(39.3)$ & & \\
\hline Consuming 3 or 4 slices of fruit/vegetables per day & $36(33.6)$ & & \\
\hline Consuming 2 or less fruits/vegetables per day & $29(27.1)$ & & \\
\hline \multicolumn{4}{|l|}{ Daily wholegrain product consumption } \\
\hline Yes & $52(48.6)$ & & \\
\hline No & $55(51.4)$ & & \\
\hline \multicolumn{4}{|l|}{ Fluid intake } \\
\hline Consuming 10 cups/glasses or more per day & $33(30.8)$ & & \\
\hline Consuming 6-9 cups/glasses per day & $38(35.5)$ & & \\
\hline Consuming 5 cups/glasses or less per day & $36(33.6)$ & & \\
\hline \multicolumn{4}{|l|}{ Personal Beliefs } \\
\hline \multicolumn{4}{|l|}{ Tendency to constipation } \\
\hline Yes & $35(32.7)$ & & \\
\hline No & $72(67.3)$ & & \\
\hline \multicolumn{4}{|l|}{ Laxative use for constipation } \\
\hline Yes & $24(22.4)$ & & \\
\hline No & $83(77.6)$ & & \\
\hline Subscale 2 & & $0-4$ & $0.62 \pm 1.30$ \\
\hline \multicolumn{4}{|l|}{ Difficulty in bowel excretion in hospital toilets } \\
\hline Yes & $20(18.7)$ & & \\
\hline No & $87(81.3)$ & & \\
\hline \multicolumn{4}{|l|}{ Problems during bedpan use } \\
\hline Yes & $12(11.2)$ & & \\
\hline No & $95(88.8)$ & & \\
\hline Subscale 3 & & $0-11$ & $2.14 \pm 2.16$ \\
\hline \multicolumn{4}{|l|}{ Physiological conditions } \\
\hline Metabolic diseases & $0(0.0)$ & & \\
\hline Pelvic conditions & $10(9.3)$ & & \\
\hline Neuromuscular diseases & $8(7.5)$ & & \\
\hline Endocrine diseases & $24(22.4)$ & & \\
\hline Colorectal/Abdominal diseases & $46(43.0)$ & & \\
\hline \multicolumn{4}{|l|}{ Psychological conditions } \\
\hline Psychiatric diseases & $19(17.7)$ & & \\
\hline Learning disorders or dementia & $0(0.0)$ & & \\
\hline Subscale 4 & & $0-10$ & $4.02 \pm 2.49$ \\
\hline \multicolumn{4}{|l|}{ Drugs b } \\
\hline Antiemetic & $47(43.9)$ & & \\
\hline Calcium channel blockers & $13(12.1)$ & & \\
\hline Iron preparations & $1(0.9)$ & & \\
\hline Anticholinergic drugs & $11(10.2)$ & & \\
\hline Cytotoxic chemotherapy & $1(0.9)$ & & \\
\hline Analgesics & $80(85.6)$ & & \\
\hline Total score & & $1-33$ & $11.71 \pm 7.81$ \\
\hline
\end{tabular}

\footnotetext{
a Data are presented as No. (\%).
}

$\mathrm{b}$ More than one drug were used. 
Celik S et al.

According to CRAS items, most of the patients were able to move independently (52.3\%), consumed 5 slices or more fruits/vegetables per day (39.3\%), consumed 6 - 9 cups/glasses of liquids (35.5\%), consumed no daily wholegrain products (51.4\%), had no believe in having tendency towards constipation (67.3\%), did not use laxative for constipation (77.6\%), had no difficulty in bowel elimination in hospital toilets (81.3\%) and did not experience difficulties in using bedpan (88.8\%) based on CRAS, as shown in Table 3. Furthermore, most of the patients had colorectal/abdominal diseases (43.0\%) and $85.6 \%$ were used analgesics (Table 3 ). CRAS scores are shown in Table 3. According to this table, the CRAS mean score of the patients was $11.71 \pm 7.81$ in the study.
According to the CRAS scores, patients had a moderate risk. The patients obtained higher scores in the subscale 1(4.93 \pm $1.86)$, lower scores in the subscale $2(0.62 \pm 1.30)$.

Table 4 shows that educational level of the patients has decreased the risk scores for constipation in a statistically significant way $(\mathrm{P}<0.05)$. It was determined that other demographic characteristics were of higher score with regard to CRAS. However, there was no statistically significant difference ( $\mathrm{P}>0.05)$.

The majority of the sample $(72 \% ; n=77)$ lacked bowel elimination problem during postoperative period. Demographic characteristics of the patients had no effect on postoperative bowel elimination problem $(\mathrm{P}>0.05)$.

Table 4. Difference in CRAS According to Sociodemographic Variables

\begin{tabular}{|c|c|c|}
\hline & $\mathrm{X} \pm \mathrm{SD}$ & Statistical Test/P \\
\hline Age, $y$ & $11.81 \pm 3.94$ & $r=0.08 \mathrm{P}=0.412$ \\
\hline Gender & & $\mathrm{t}=1.34 ; \mathrm{P}=0.185$ \\
\hline Female & $12.36 \pm 4.30$ & \\
\hline Male & $11.33 \pm 3.56$ & \\
\hline Marital status & & $Z=-3.11 ; P=0.753$ \\
\hline Married & $11.72 \pm 3.84$ & \\
\hline Single & $12.43 \pm 4.66$ & \\
\hline Educational level & & $K W=19.47 ; P=0.001$ \\
\hline Illiterate & $15.05 \pm 3.56$ & \\
\hline Primary school & $11.59 \pm 3.91$ & \\
\hline High school & $10.30 \pm 2.95$ & \\
\hline University and higher & $10.00 \pm 3.33$ & \\
\hline Professional status & & $\mathrm{KW}=4.51 ; \mathrm{P}=0.344$ \\
\hline Self-employed & $10.71 \pm 3.70$ & \\
\hline Office job & $9.83 \pm 2.13$ & \\
\hline Housewife & $12.56 \pm 4.04$ & \\
\hline Retired & $11.43 \pm 3.78$ & \\
\hline Other & $13.00 \pm 4.95$ & \\
\hline Economic status & & $\mathrm{t}=-0.48 ; \mathrm{P}=0.623$ \\
\hline Good & $11.75 \pm 3.95$ & \\
\hline Bad & $12.36 \pm 4.03$ & \\
\hline Life style & & $\mathrm{t}=0.14 ; \mathrm{P}=0.886$ \\
\hline Sedentary & $11.90 \pm 4.12$ & \\
\hline Active & $11.78 \pm 3.89$ & \\
\hline Body mass index & & $K W=6.13 ; P=0.182$ \\
\hline Underweight & $11.80 \pm 2.58$ & \\
\hline Normal & $12.38 \pm 3.40$ & \\
\hline Overweight & $11.23 \pm 4.01$ & \\
\hline Obese & $12.76 \pm 4.62$ & \\
\hline Morbid obese & $10.50 \pm 4.14$ & \\
\hline History of constipation & & $\mathrm{t}=0.75 ; \mathrm{P}=0.453$ \\
\hline Yes & $12.16 \pm 3.53$ & \\
\hline No & $11.57 \pm 4.21$ & \\
\hline Alternative treatments for constipation & & $\mathrm{t}=1.19 ; \mathrm{P}=0.237$ \\
\hline Yes & $12.40 \pm 3.59$ & \\
\hline No & $11.46 \pm 4.12$ & \\
\hline History of surgical intervention & & $\mathrm{t}=1.55 ; \mathrm{P}=0.121$ \\
\hline Yes & $12.61 \pm 4.15$ & \\
\hline No & $11.38 \pm 3.78$ & \\
\hline
\end{tabular}


Celik S et al.

\begin{tabular}{|c|c|c|c|}
\hline & \multicolumn{2}{|c|}{ Bowel Elimination } & \multirow[t]{2}{*}{ Statistical Test/ P } \\
\hline & Yes & No & \\
\hline CRAS Score & $11.56 \pm 2.93$ & $11.70 \pm 4.24$ & $t=-0.15 ; P=0.872$ \\
\hline Duration of hospitalization, $d$ & $5.30 \pm 1.78$ & $7.40 \pm 6.26$ & $\mathrm{t}=-1.80 ; \mathrm{P}=0.073$ \\
\hline Duration of surgery, d & $177.33 \pm 95.77$ & $209.22 \pm 96.75$ & $\mathrm{t}=-1.53 ; \mathrm{p}=0.125$ \\
\hline Time to oral feeding after surgery, $d$ & $2.59 \pm 1.01$ & $3.03 \pm 0.78$ & $\mathrm{t}=-2.20 ; \mathrm{p}=0.031$ \\
\hline Postoperative mobilization time, $\mathrm{d}$ & $1.87 \pm 0.77$ & $2.23 \pm 0.87$ & $\mathrm{t}=-2.01 ; \mathrm{P}=0.042$ \\
\hline Type of the surgery & & & $\chi^{2}=12.88 ; P=0.015$ \\
\hline Stomach & $2(6.7)$ & $21(27.3)$ & \\
\hline Colon & $10(33.3)$ & $30(39.0)$ & \\
\hline Gall bladder & $3(10.0)$ & $10(13.0)$ & \\
\hline Hernia repair & $8(26.7)$ & $5(6.5)$ & \\
\hline Other & $7(23.3)$ & $11(14.3)$ & \\
\hline Type of anesthesia & & & $\chi^{2}=4.54 ; P=0.067$ \\
\hline General & $27(90.0)$ & $76(98.7)$ & \\
\hline Local & $3(10.0)$ & $1(1.3)$ & \\
\hline Form of the surgery & & & $\chi^{2}=0.30 ; P=0.584$ \\
\hline Open & $24(80.0)$ & $65(84.4)$ & \\
\hline Laparoscopic & $6(20.0)$ & $12(15.6)$ & \\
\hline Postoperative oral feeding & & & $\chi^{2}=2.44 ; P=0.113$ \\
\hline Yes & $27(90.0)$ & 59() 76.6 & \\
\hline No & $3(10.0)$ & $18(23.4)$ & \\
\hline Postoperative analgesic use & & & $\chi^{2}=0.77 ; P=0.672$ \\
\hline No use & $7(23.3)$ & $20(26.0)$ & \\
\hline Non-opioids use & $16(53.3)$ & $34(44.2)$ & \\
\hline Opioids use & $7(23.3)$ & $23(29.9)$ & \\
\hline Postoperative antiemetic use & & & $\chi^{2}=3.59 ; P=0.051$ \\
\hline No & 22() 73.3 & $41(53.2)$ & \\
\hline Yes & $8(26.7)$ & $36(46.8)$ & \\
\hline
\end{tabular}

${ }^{\mathrm{a}}$ Data are presented as Mean $\pm \mathrm{SD}$.

Table 5 shows the effect of patients' clinical characteristics related to bowel elimination. The CRAS mean score of the patients did not have any effect on postoperative bowel elimination. The type of the surgery $(P<0.05)$, starting time for oral feeding after the surgery $(\mathrm{P}<0.05)$ and mobilization $(\mathrm{P}<0.05)$ were effective on postoperative bowel elimination. Postoperative bowel elimination could not usually be provided in patients undergone stomach (27.3\%) and colon (39.0\%) surgeries. Moreover, bowel elimination did not occur in the patients who started oral feeding (3.03 \pm 0.78 days) and mobilization ( $2.23 \pm 0.87$ days) later. Type of the surgery and anesthesia, surgical intervention process, duration of starting to oral feeding after the surgery, taking analgesic and antiemetic drugs, and duration of hospitalization, had no statistically significant effect on postoperative bowel elimination $(P>0.05)$.

\section{Discussion}

The present study revealed 4 important results associ- ated with constipation risk in patients undergone abdominal surgery: 1) No relationship was found between descriptive characteristics of the patients and constipation risk before the surgery, 2) Bowel elimination problem was high in patients after the surgery, 3) The presence of moderate constipation risk in patients before the surgery was not effective on bowel elimination, 4) Some variables regarding surgical intervention process were found to be effective in providing bowel elimination after the surgery.

There was a moderate constipation risk in patients found by constipation risk assessment before the surgery in the hospital (11.71 \pm 7.81$)$. It is thought that this finding is due to factors such as lack of movement observed in most of the patients, inability to consume fiber and wholegrain products and fluid intake, colorectal/abdominal discomfort, and drug use. The result showed similarity with the previous studies. In previous studies, these variables had a positive effect on the regulation of bowel movements, formation, and the amount of defecation $(5,10,19-23)$. 
Celik S et al.

According to the literature, small intestine returns to its normal function in a couple of hours after the surgery. This time would be 24 - 48 hours for stomach surgery and 48 - 72 hours for colon surgery (13). In this study, most of the patients did not present with bowel elimination at second night after operation, whereas in previous studies regarding abdominal surgeries, the bowel elimination problem often occurred (17) and it did not occur altogether in $3-57 \%$ of the patients (18).

No relationship was found between bowel elimination of the patients and mean preoperative CRAS scores. Demographic characteristics of the patients such as age, sex, marital status, body mass index, occupation, economic status, life style, previous constipation, and surgical history had no effect on CRAS mean scores. Similarly, these characteristics did not show any effect on postoperative bowel elimination of the patients. The result suggested that abdominal surgery rather than demographic characteristics affect bowel elimination in this patient group. In similar studies, it was also reported that the constipation complaints usually increased in the following people: older ages $(6,21,22)$, women $(2,6)$, patients using drugs containing anticholinergic drugs (23), patients consuming less fiber-containing food $(2,10,21)$, physically inactive people $(10,21,23)$, patients taking in sufficient fluid $(10,21)$, those having more constipation complaints $(6,24)$, patients with disease history that can cause constipation (23), patients with low education level (3), singles (3), overweight people (21), and patients with a previous surgical history (3).

In this study, type of the surgery, starting oral feeding after the surgery and timing of the mobilization were found to be effective factors on bowel elimination during postoperative period. Accordingly, postoperative bowel elimination could not be provided in the patients undergone a colon surgery, started enteral feeding within a mean of 3 days, and those who were mobilized on the second day. In recent studies, it was reported that early mobilization and early enteral feeding are beneficial for bowel functions and help patients to return to their normal bowel functioning within 12 - 72 hours $(3,25-27)$. Furthermore, the surgery type, anesthesia, duration of surgery, postoperative analgesic use and duration of hospitalization are found to negatively affect bowel elimination, but the result did not show a statistically significant difference. The effect of these variables on bowel elimination was emphasized in the previous studies. It was proven that epidural anesthesia returns bowel functions earlier $(3,24,28)$. Concerns over lower bowel functions emerged as a result of open surgical interventions, which actually traumatize tissues. They produce long-term complications and their followup period is painful along with the increase use of opioids $(22,25,27,29)$. Therefore, laparoscopic surgery is recommended in which the effect of traumatic level on tissues, incision size, duration of surgical intervention, opioids necessity, pain level, and duration of hospitalization are less compared to open surgical intervention $(3,27)$.
There is a constipation risk in the patients who have undergone abdominal surgery since bowel elimination problem is high. Surgery and postoperative practices are effective on bowel elimination problem after abdominal surgery. However, moderate constipation risk before the surgery and demographic characteristics of the patients are not effective on this condition.

\subsection{Study Limitations and Strengths}

Results of the study are limited to the sample group and cannot be generalized. To overcome this problem, studies must be conducted on larger samples. Second, the present study has a limited number of affecting factors examined. Third limitation is the cross-sectional design of this study, which prohibited it from exploring causal relationships. Use of instruments with known reliability and validity in a sample is an asset of this study. We believe that our study is of prime value since no previous study was conducted in both preoperative and postoperative period and regarding the data provided in this study, it will offer a more comprehensive evaluation opportunity for the future studies.

\section{Acknowledgements}

We would like to thank all patients in General surgery wards of Bülent Ecevit University Hospital.

\section{Authors' Contributions}

Study concept and design as well as development of the methods: Sevim Celik and Nurdan Yalcin Atar; Data collection: Nilgun Ozturk, Guler Mendes, Figen Kuytak, Esra Bakar, Duygu Dalgiran, and Sumeyra Ergin; Data analysis and interpretation: Sevim Celik; and Writing the manuscript draft: Sevim Celik, Nurdan Yalcin Atar. All the authors contributed to the reading, and revising of the manuscript, and approving the final version.

\section{References}

1. Asdemir N, Celik SS. Hastaların cerrahi girișim sonrası abdominal distansiyona yönelik deneyimleri. Ege Univ Sch Nurs J 2010;26(3):23-31.

2. Uysal N, Khorshid L, Eser I. healthy young bireylerde konstipasyon sorununun belirlenmesi. TAF Prev Med Bull. 2010;9(2):127-32.

3. Sendir M, Buyukiylmaz F, Asti T, Gurpinar S, Yazgan I. Postoperative constipation risk assessment in Turkish orthopedic patients. Gastroenterol Nurs. 2012;35(2):106-13.

4. Lee JL, Yang SS, Park IJ, Yu CS, Kim JC. Comparison of abdominal and perineal procedures for complete rectal prolapse: an analysis of 104 patients. Ann Surg Treat Res. 2014;86(5):249-55.

5. Raahave D. Faecal retention: a common cause in functional bowel disorders, appendicitis and haemorrhoids--with medical and surgical therapy. Dan Med J. 2015;61(3):B5031.

6. Koo HY, Park KJ, Oh JH, Kang SB, Oh ST, Lee WY. Investigation of clinical manifestations in korean colorectal cancer patients. Ann Coloproctol. 2013;29(4):139-43.

7. Kutlu AK, Yilmaz E, Cecen D, Eser E. The reliability and validity of the Turkish version of the constipation risk assessment scale. Gastroenterol Nurs. 2011;34(3):200-8.

8. Xin HW, Fang XC, Zhu LM, Xu T, Fei GJ, Wang ZF, et al. Diagnosis 
of functional constipation: agreement between Rome III and Rome II criteria and evaluation for the practicality. J Dig Dis. 2014;15(6):314-20.

9. Camilleri M. Inclusion criteria for pharmacodynamic and clinical trials in chronic idiopathic constipation: pitfalls in using Rome III for functional constipation. Therap Adv Gastroenterol. 2011;4(3):159-63.

10. Ayaz S, Hisar F. The efficacy of education programme for preventing constipation in women. Int J Nurs Pract. 2014;20(3):275-82.

11. Rasmussen LS, Pedersen PU. Constipation and defecation pat tern the first 30 days after thoracic surgery. Scand J Caring Sci. 2010;24(2):244-50.

12. Miaskowski C. A review of the incidence, causes, consequences, and management of gastrointestinal effects associated with postoperative opioid administration. J Perianesth Nurs. 2009;24(4):222-8.

13. Richmond JP, Wright ME. Establishing reliability and validity of a constipation risk assessment scale. Journal of Orthop Nurs. 2008;12(3-4):139-50.

14. Richmond JP, Wright ME. Development of a constipation risk assessment scale. Journal of Orthopaedic Nursing. 2006;10(4):186-97.

15. Richmond JP, Wright ME. Development of a constipation risk assessment scale. Clin Eff Nurs. 2005;9(1-2):37-48.

16. Story SK, Chamberlain RS. A comprehensive review of evidencebased strategies to prevent and treat postoperative ileus. Dig Surg. 2009;26(4):265-75.

17. Basse L, Madsen JL, Kehlet H. Normal gastrointestinal transit after colonic resection using epidural analgesia, enforced oral nutrition and laxative. BrJ Surg. 2001;88(11):1498-500.

18. Richmond JP. Development and validation of a constipation risk asessment scale for use in clinical practice. University Ulster; 2002.

19. Rajput M, Saini SK. Prevalence of constipation among the gen- eral population: a community-based survey from India. Gastroenterol Nurs. 2014;37(6):425-9.

20. Ribas Y, Saldana E, Marti-Rague J, Clave P. Prevalence and pathophysiology of functional constipation among women in Catalonia, Spain. Dis Colon Rectum. 2011;54(12):1560-9.

21. Costilla VC, Foxx-Orenstein AE. Constipation in adults: diagnosis and management. Curr Treat Options Gastroenterol. 2014;12(3):310-21.

22. Monmai P, Tilokskulchai F, Putwatana P, Kawinwonggowit V. The effects of a constipation prevention program on incidence and severity of contipation in hospitalized elderly undergoing hip surgery. J Nurs Sci. 2011;29(4):10-7.

23. Costilla VC, Foxx-Orenstein AE. Constipation: understanding mechanisms and management. Clin Geriatr Med. 2014;30(1):107-15.

24. Feo CV, Lanzara S, Sortini D, Ragazzi R, De Pinto M, Pansini GC, et al. Fast track postoperative management after elective colorectal surgery: a controlled trail. Am Surg. 2009;75(12):1247-51.

25. Artinyan A, Nunoo-Mensah JW, Balasubramaniam S, Gauderman J, Essani R, Gonzalez-Ruiz C, et al. Prolonged postoperative ileusdefinition, risk factors, and predictors after surgery. World J Surg. 2008;32(7):1495-500

26. Sindell S, Causey MW, Bradley T, Poss M, Moonka R, Thirlby R. Expediting return of bowel function after colorectal surgery. Am J Surg. 2012;203(5):644-8.

27. Feng HQ, Dai L, Ma SH, Kang XZ, Yang YQ, Chen KN. [Impact of early enteral nutrition on the intestinal motility of patients after esophagectomy]. Zhonghua Wei Chang Wai Ke Za Zhi. 2012;15(9):957-9.

28. Johnson MD, Walsh RM. Current therapies to shorten postoperative ileus. Cleve Clin J Med. 2009;76(11):641-8.

29. Garnock-Jones KP. Naloxegol: a review of its use in patients with opioid-induced constipation. Drugs. 2015;75(4):419-25. 